\title{
The Birkeland Terrella Experiments and their Importance for the Modern Synergy of Laboratory and Space Plasma Physics
}

\author{
$\underline{\text { K. Rypdal and T. Brundtland }}$
}

Department of Physics, University of Tromsø, 9037 Tromsø, Norway

\begin{abstract}
A study of the evolution of Kristian Birkeland's theories of cosmical physics is presented, with special reference to his laboratory gas-discharge experiments. It is found that his most important thoughts were molded from an intense cross-fertilization between laboratory experiments, geophysical observations and mathematical modelling. Occasionally, original ideas of fundamental importance in the cosmic context emerged from unexpected laboratory results. Possible implications for a sound cross-disciplinary approach to modern plasma science are discussed.
\end{abstract}

\section{INTRODUCTION}

Although plasma physics emerged as an independent physical discipline as late as in the 1950's, the roots can be traced back to the nineteenth century, even to the time before the electron was discovered by J. J. Thomson in 1897. At that time one did not have a clear conception of the fourth state of matter, but a few great scientists developed through laboratory experiments in discharge tubes and geophysical observations fundamentally correct ideas about the plasma nature of the sun, the interplanetary space, and the solar terrestrial interaction. A giant among these visionaries was the Norwegian physicist and inventor Kristian Birkeland (1867-1917), whose outstanding scientific work has received increasing recognition throughout the last two decades of active space exploration.

Even though modern space science continues to rediscover the deep truth of many of Birkeland's ideas, an even more interesting aspect of his work may be his interdisciplinary approach to scientific exploration. Birkeland aqcuired and processed information from a number of research disciplines which today are virtually non-interacting, and by bold inferences and analogies he proposed hypotheses which were not generally accepted until more than half a century after his death. Among these disciplines were electromagnetic theory, electrical engineering, laboratory gas discharges, geophysics and astrophysics. During the first decades after the end of World War II plasma science emerged as a new field that unifies the fundamental disciplines of elecromagnetic theory, statistical mechanics, kinetic theory with astrophysics, space physics and materials science. However, in the last twenty years there seems to have been a decline of consciousness about plasma science as an independent, but unifying, scientific discipline. There has been a tendency towards fragmentation of plasma science into specialities like fusion plasmas, space plasmas, weakly ionized laboratory plasmas and industrial plasma processing, and many plasma physicists find it easier to market themselves to the funding agencies as fusion scientists, space physicists, and so on. This, in turn, leads to reduced emphasis on basic plasma physics, to more specialized journals and conferences, and to reduced interdisciplinary interaction. The main lesson we can learn from Birkeland and the other great founders of plasma science is to regain faith in the unity and basic nature of our science, and to strive to tear down the walls that are erected between specialized areas.

Article published online by EDP Sciences and available at http://dx.doi.org/10.1051/jp4:1997408 


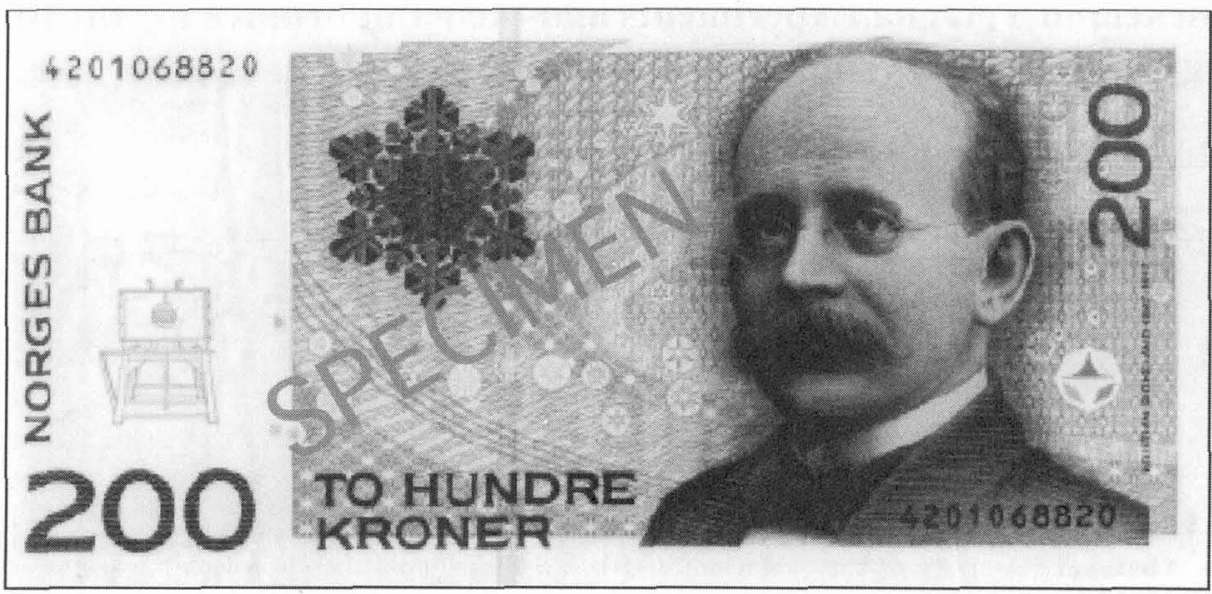

Figure 1: The $200 \mathrm{kr}$ banknote issued in 1996 in celebration of the centennial anniversary of the auroral hypothesis. To the immediate left of Birkeland's portrait one can see an auroral arc from below, rising towards the polar star. One also observes several stellar constellations. The snow crystal symbolizes the winter, when aurora is most frequently observed. To the very left is a drawing of the last and largest terrella-chamber. This chamber is now restored and at display for the public at the University of Tromsø.

\section{A BRIEF BIOGRAPHY}

Kristian Olaf Bernhard Birkeland was born in Christiania (now Oslo) in Norway on December 13th, 1867. He studied physics at University of Christiania 1885-90, and in the years 1890-93 he worked as a research assistant at the University with experimental and theoretical studies on electromagnetic wave propagation. In 1893 he went abroad to continue his studies in Paris, Geneva, Bonn and Leipzig. In Paris he worked with H. Poincaré, P. Appell and E. Picard, and did his first experiments on cathode rays in a monopole magnetic field. In Switzerland he collaborated with geophysicist like E. Sarasin, and it was probably here Birkeland got his strong passion for the study of geomagnetism and polar aurora. In Bonn he worked in Heinrich Hertz' radio-laboratory. He did not obtain a fruitful collaboration with Hertz, who was ill and died shortly after, but worked for some time with P. Lénard.

Birkeland returned to a position at the University of Christiania in 1895 and immediately started to do experiments on gas dicharges and cathode rays. In 1896 he performed experiments where cathode rays were attracted by a magnetic pole, and he could produce a glowing light in the vicinity of this pole reminiscent of the northern light (polar aurora) [1]. This observation made him state his auroral hypothesis - the aurora must be produced by cathode rays attracted by the earth's magnetic poles, and in some way or another the energy must be derived from the sun. The formulation of this hypothesis initiated an extensive experimental, observational and theoretical programme to unveil Nature's secrets about the origin of auroras, geomagnetic storms, the nature of solar activity, comets, planetary rings and even the origin of the solar system istelf. In 1996, at the centennial anniversary of Birkeland's auroral hypothesis, a bank note was issued by the Bank of Norway (Fig. 1). In addition to the portrait of Birkeland it contains a number of details related to auroral research. In particular, one can see a drawing of the last and largest of his terrella experiments.

In the period 1897-1903 Birkeland organized three expeditions to the Arctic to make geomagnetic and other geophysical measurements. During the latest of these expeditions, "The Norwegion Aurora Polaris Expedition 1902-1903", four observatories were set up at different locations in the Arctic, 
collecting geophysical data for a period of approximately a year. These data were combined with data from a large number of geomagnetic observatories around the globe and with results from laboratory terrella-experiments, and made the foundation for far-reaching theories about the cause of magnetic storms and terrestrial magnetism. This work was summarized in an 800 page treatise. The first part was published in 1908 and the second in 1913 [2].

The first series of terrella experiments were performed in glass tubes of variable shape and size in the period 1900-1908. They were conducted in between and after the arctic expeditions, and were obviously a very useful tool for Birkeland when he was striving with making sense out of the extensive mass of geophysical data aqcuired. During the work with the second part of his treatise he felt constrained by certain limitations of the small glass tube experiments, and started to build a series of box-shaped chambers with flat glass walls. Experiments with four different box-chambers of increasing size were conducted in the period 1908-1913, and the results were published in the second part of his treatise.

In 1903 Birkeland started a collaboration with the Norwegian mathematician and auroral physicist Carl Størmer. Henri Poincaré had already learnt about Birkeland's early cathode ray experiments from 1896, and immediately presented a solution of the equation of motion for a charged particle in a magnetic monopole field [3]. Birkeland elaborated further on this problem in an experimental and theoretical paper from 1898 [4]. The monopole problem is integrable, but the corresponding dipole problem is not, and it was this problem Birkeland wanted the gifted young Størmer to solve. For Størmer this task became a lifelong enterprise, and his calculations became a cornerstone in Birkeland's theories [5].

During his entire career Birkeland spent a lot of time on practical, industrial research and technical inventions. Among his most famous inventions are his electromagnetic gun and the development of a plasma furnace for oxidation of the air's nitrogen, which soon was developed into one of Norway's most profitable industries. Birkeland got 59 patents, and made a considerable fortune on some of them. This money was spent primarily to fund his own research. Not all of his ideas came to immediate practical application. As early as in 1906 he was searching for funds to start a project on devloping methods for the release of atomic energy.

Towards the end of his short life, Birkeland's health was gradually reduced. He moved permanently to Egypt in 1913, and hoped the warm climate would do him well. Here he could also study one of his latest passions - the zodiacal light. However, his physical and mental health did not get better. In March 1917 he decided to go back to Norway, not through the war-ridden Europe, but by sea to Japan and then by rail through Siberia. He wanted to stay a few months in Japan, but on the 15 th of June he was found dead in his hotel room with a handgun and a small bag of veronal on his table. ${ }^{1}$

\section{ORIGIN AND SIGNIFICANCE OF THE AURORAL HYPOTHESIS}

When Birkeland came back to Norway in summer 1895 he had become very interested in gas discharges, which was a popular field of research at that time. He obtained a position at the university, at an age of 28, and during a few hectic months in the fall 1895 he established a laboratory for gas discharge research. He also began to prepare a course in "gas discharges and experiments" with a planned start in February 1896. In January 1896 newspapers all around the world wrote about the new rays discovered by W. C. Röntgen in Germany [9] . In Christiania, Birkeland commented on this news with articles in the newspapers [10]. Less than one month after Röntgen made his first public demonstration, Birkeland demonstrated X- rays for a group of engineers, physicists and physicians. On March 23, he gave a public performance, where he could also demonstrate artificial northern

\footnotetext{
${ }^{1}$ For a more complete biography we refer to A. Egeland and E. Leer, "Professor Kr. Birkeland: His Life and Work" [6], to A. Egeland, "Kristian Birkeland, the Man and the Scientist" [7], and to A. Egeland, "Kristian Birkeland, mennesket og forskeren" [8].
} 


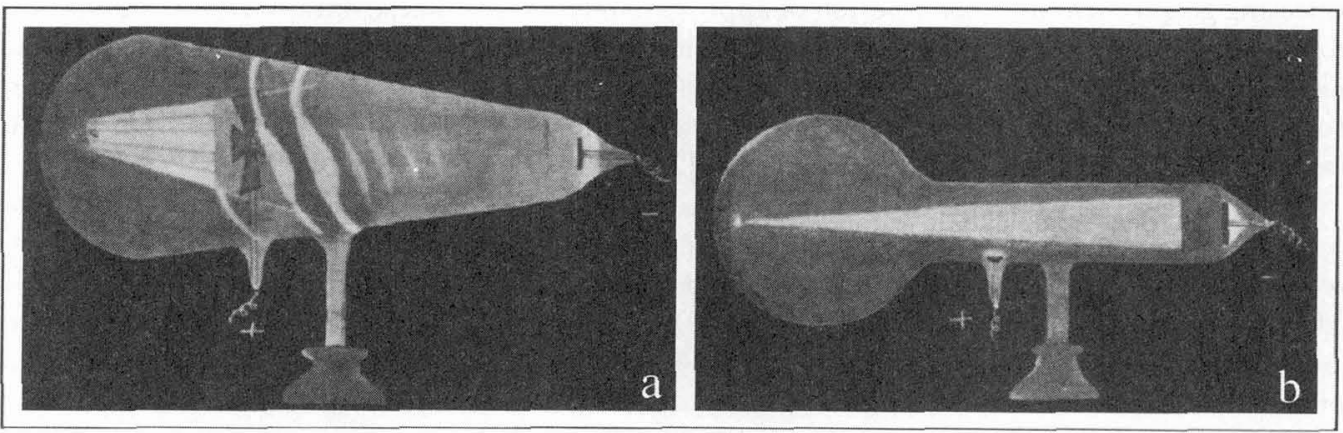

Figure 2: (a) The first production of artificial aurora in March 1896. (b) The set-up Birkeland used for writing his initials onto glass by means of cathode rays.

light in a gas discharge tube by letting "air glow in stripes as the Aurora, by magnetic influence on cathode rays". He also suggested to send photographic plates, only sensitive for cathode rays, up to high altitudes with balloons, to investigate the relationship between aurora and cathode rays.

In April 1896 he published an article [11], where he described several different experiments with gas discharges. The paper dealt with magnetic lenses, magnetic spectra and discharges that have a remarkable resemblance to the Aurora Borealis. In one experiment he was able to focus the cathode rays by external magnets, to the size of a needle point on the inner side of the glass wall. The action of such a beam was so intense and hot that if it was allowed to travel over the surface of the glass by moving the magnets, it left the mark of its track by splitting off glass particles from the wall. In this way, writings could be etched on the glass. Birkeland was easily able to write his initials, Kr. B. on the inside. The discharge tubes used for these experiments are shown in Fig. 2.

These were very important results in themselves, but the most far reaching consequences of this experimental work is contained in the inferences drawn in the last paragraph:

...Several times phenomena have been described, which show that cathode rays are drawn towards a magnetic pole. This observation is considered to be of interest in the connection with the theory of the Aurora Borealis. Paulsen, the Danish meteorologist, considers that the Aurora Borealis is due to the phosphorescence of the air by cathode rays in the highest strata of the atmosphere. The greatest difficulty in this theory has been to explain why these displays are confined to a zone surrounding the magnetic pole of the earth, and from whence the energy comes which gives rise to these rays. After what has been said above, it may be assumed that the rays are attracted by the earth's magnetic pole, and that in some way or other the energy is derived from the sun. The latter hypothesis is at least supported by the fact of the diurnal variations of the northern lights, and the cyclic changes which correspond with the 11 year periods of maximum solar activity.

The hypothesis stated above was not entirely new, although it was competing with a wealth of other colorful ideas about the origin of the aurora. About $1878 \mathrm{H}$. Bequerel suggested that particles were shot off from sunspots and were guided by the Earth magnetic field to the auroral zone. A similar idea was proposed by E. Goldstein. What distinguished Birkeland's hypothesis from the others is that he was guided by controlled experiments. This made his idea more than a suggested explanation of a phenomenon, it was a hypothesis formulated for immediate experimental test, and for two decades to come it guided him through what perhaps was the most extensive experimental and observational programme in the world to that date.

In the first years after the auroral hypothesis was formulated Birkeland conducted more laboratory work on cathode rays and magnetism. He had several publications on this subject, but he was also 
studying sunspots and cosmic phenomena. Birkelands later wrote proudly and with great satisfaction that J. J. Thomson, in his ${ }^{\cdot c l a s s i c ~ p a p e r ~ o n ~ t h e ~ n a t u r e ~ o f ~ t h e ~ c a t h o d e ~ r a y s ~ f r o m ~} 1897$ [12], had taken some of his discoveries from this period as a starting point when proving that the atom is not the smallest unit of matter.

Birkeland, who became professor in September 1898, campaigned for getting an observatory for auroral studies established on the mountain of Haldde, near Alta in northern Norway. The Norwegian government provided funds, and Birkeland and an assistant stayed in an observation hut at the mountain top during the winter of 1899-1900. The results from this expedition are described in the book "Expedition Norvegienne 1899-1900" [13]. This book, published in 1901, also has a chapter on experiments with gas discharges performed in the laboratory in Christiania. One of the many experiments described in this book is a discharge set-up that showed spectacular phenomena due to electrostatic actions. He was able to guide the visible discharges towards the glass wall by putting his finger at the outside, not unlike modern "plasma balls" made for decorations.

He also described experiments with a spherical discharge tube placed on top of a big electromagnet, and with the anode located at the center of the tube. With this arrangement he was able to create some discharges of ravishing beauty, playing and dancing like the merry dancers of the auroral bands. He concluded this experiment with the following phrase:

The produced bands present then such an analogy with the auroral bands, that when witnessing this experiment, no doubt is possible, we see the evidence that the two phenomena are strongly related.

With this successful experiment a period in Birkeland's laboratory activity was over. After four years of hard work with classical gas discharge tubes, studying X-rays, influence on cathode rays by magnets and discharges which resemble the Aurora Borealis, he now turned to a new class of experiments. During the hibernation at the mountain top in the North he had got greater ideas.

\section{EVOLUTION OF EXPERIMENTS AND IDEAS}

In October 1900, the Norwegian electrical engineering journal, "Elektroteknisk Tidsskrift", had a note called "The Auroral Expedition." It contained a short description of Birkeland's second expedition to the Arctic. Birkeland was now back in Christiania and had already done some new experiments with a "spherical electromagnet". He would like to test some details of his auroral theory, based on recent observations during the expedition. In two gas discharge set-ups, he produced results which he interpreted as current whirls around a metallic sphere painted with phosphorescent material, with an electromagnet inside. The spheres in each case simulated the Earth with its magnetic field. The currents were created by a cold cathode discharge between electrodes in the tube, and were seen on the terrella as illuminations of the phosphorescent paint and as wedges of light with embedded rays in the rarefied gas. He could see two narrow rings of light around the poles of the sphere which was interpreted as aurora in miniature. The observations in the Arctic combined with these successful experiments were for Birkeland a great step towards a verification of his auroral hypothesis.

In the book from the expedition [13], which was published the next spring, he had a chapter describing in detail these experiments. Later he named the spherical electromagnet a terrella (little Earth) after the small magnets or loadstones used as Earth models back in the sixteenth century by William Gilbert (1540-1603), and described in the book "De Magnete" [14].

The idea of using a magnetizable sphere in a gas discharge opened up a new and great field of research for Birkeland. Almost all his future laboratory physics would be focused on this miniature Earth. In the hectic years 1900-1913 he used many terrellas for different purposes, varying in size and construction. In addition to studying artificial aurora he also used the terrellas for simulating solar phenomena, comets and the rings of Saturn. Ten different terrellas are described with diameters from 


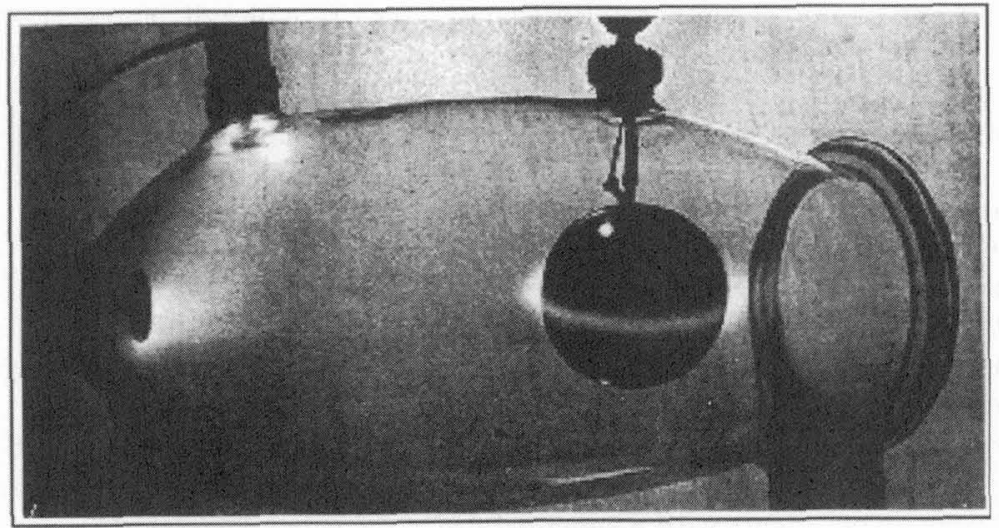

Figure 3: This simulation of "Equatorial Rings of Light" was performed in the first 12 liter glass tube with a $10 \mathrm{~cm}$ terrella. It was excited by an induction machine giving $6000 \mathrm{~V}$, and with $10 \mathrm{~A}$ terrella magnetizing current. In this experiment, he ran the discharge between a cathode (left) and a separate anode (top left). Since no circuit diagram is given, the potential of the terrella surface is not known.

2.5 to $36 \mathrm{~cm}$. In the first experiments, performed in the autumn of 1900, Birkeland used two terrellas, 5.0 and $7.5 \mathrm{~cm}$ in diameter. The electromagnets with core and windings were shaped as spheres and surrounded with a thin crust of brass covered with a coat of barium platinocyanide. Birkeland was well aware that he could not achieve quantitative similarity to natural magnetic conditions. With a terrella diameter of $7.5 \mathrm{~cm}$ and thereby $1.7 \times 10^{8}$ times smaller than the Earth diameter, it would require an analogous magnetic field surrounding the sphere $1.7 \times 10^{8}$ times stronger than the intensity of the geomagnetic field, certainly impossible to achieve in practice. Fortunately he observed that the luminous phenomena did not vary too much with the magnetic force of the terrella, provided that the force already had reached a considerable value.

All the other terrella experiments of Birkeland were described in the treatise from the third arctic expedition [2], which covers his lab work from 1901-1913. Many of the experiments were performed with terrellas where the coil and thus the magnetic axis were tilted relative to the vertical axis. During the experiments he was able to rotate the terrellas around the vertical axis, and in this way he studied the effect of the eccentricity of the Earth's magnetic poles on the aurora.

When first starting systematic terrella experiments he used cylindrical tubes, with a volume of approximately 12 liters, as shown in Fig. 3. Experiments in this tube were also used for comparison with the orbit calculations of Carl Størmer. For direct comparison with experiments wire models were made for visualization of the trajectories in space, as shown in Fig. 4.

When simulating the aurora in the laboratory Birkeland had to give the terrella some sort of atmosphere. This problem was solved in various ways. In the early weak discharges the surface of the terrella was covered with a phosphorescent paint that produced visible light when hit by the rays. Later he described another method that made it easier to observe rays in the surrounding space. By running a high current through the magnetizing coil, the terrella surface became hot and gave off gas. He then reduced the magnetic field to the desired value, ignited the discharge, and took pictures. A third method was to cover the surface with a thin layer of pump oil, which evaporated during the dicharge.

In Fig. 4 is shown a terrella with a large vertical screen. With low intensity discharges it was only possible to see where the cathode rays hit the terrellas by the phosphorescense of the surface. In order to be able to see the trajectories of the rays before they hit the terrella, it was supplied with plates (called screens by Birkeland), which were also painted with phosphorescent material. There were vertical and horizontal screens, screens with holes and slits, sets of as many as eight screens 


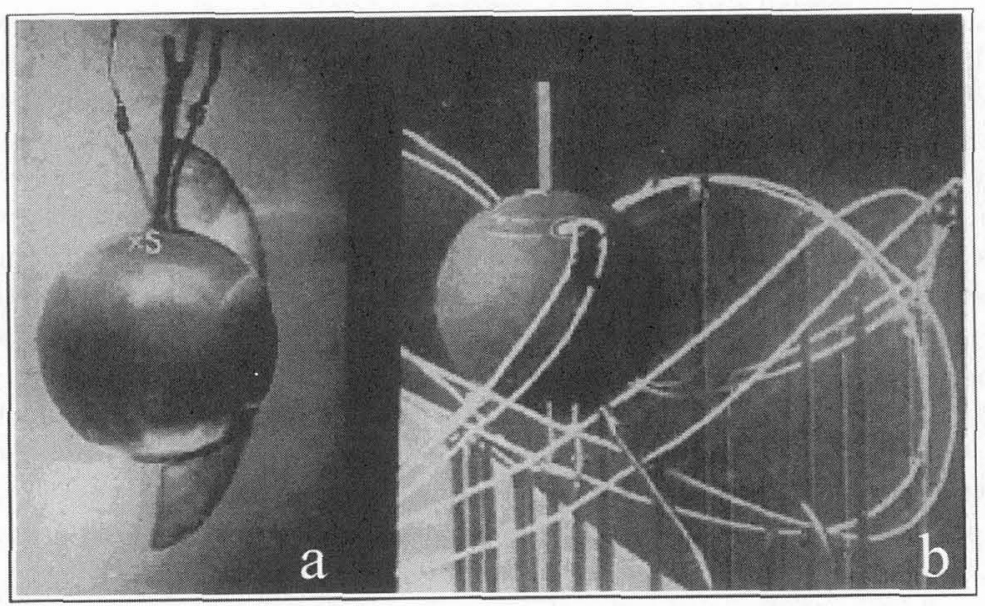

Figure 4: A comparison between a terrella experiment (left) and a model showing professor Størmer's calculated trajectories for that experiment. This experiment was performed in July 1907 in the first 12-liter glass tube, and shows illuminated regions along "the auroral zone". The calculated trajectories are for particles starting out in slightly different directions at a position corresponding to the cathode and with energies corresponding to the discharge voltage.

on one terrella, screens with pins, combinations of screens and pins pointing out from the terrella surface, and so on. The pins created shadows which provided information on the ray paths.

From 1895 to 1908 all his lab experiments, including auroral studies, were performed in fragile glass tubes where refraction of light through the curved glass walls tended to give distorted spatial information on the photographs. Guided by these shortcomings Birkeland now designed a new experimental chamber as a box, with top and bottom made of metal plates, and glass windows on the four sides. The total volume of this new box was 22 liters, the glass plates or windows had an area of approximately $20 \times 45$ and $20 \times 25 \mathrm{~cm}$ and a thickness of $2.0 \mathrm{~cm}$. They were cemented together with "Cementium" and the entire chamber was finished on the outside with picein, a tar-like, black sealing agent. With this improved construction he continued to study discharges with the purpose to gain a clear idea of the course of the rays around magnetized terrellas. One reason for continued experimental research on this problem was his scepticism to idealized mathematical models. As long as the mathematical models were not perfect, the usefulness of such calculations were limited, he claimed, with address to Størmer.

At this time, in the winter 1910-1911, Birkeland's laboratory interest turned from the aurora borealis to solar and cosmic phenomena. He started up with some quite new experiments in the 22-liter chamber, now simulating the Sun, Saturn and comet tails.

In several of his auroral experiments Birkeland had come upon phenomena which could serve as a starting point for an explanation of the zodiacal light. This light is a glow which appears in the western sky after sunset, and in the eastern sky before sunrise, at lower latitudes. He believed that this light also was due to discharges, as the aurora, and tried to simulate it in his laboratory. This experimental set-up was very similar to the one for the aurora, but the polarity of the discharge was changed. The terrella, which was without phosphorescent coating, was now negative and served as the cathode, simulating the Sun. He used one or two aluminium discs for anodes.

As far as can be ascertained from the text, this was his usual way of connecting the apparatus when doing experiments simulating zodiacal light, sunspots and the rings of Saturn. He also experimented with using the metal parts of the chambers as an electrode. His explanation of the zodiacal light was that clouds of "atomic dust" originating from the Sun were spread out in a very thin layer in the Sun's 
equatorial plane, and were illuminated by a some sort of cosmic discharge. He demonstrated this for the first time by running discharges with an $8 \mathrm{~cm}$ terrella. With the terrella highly magnetized, and with a low discharge current he could create a flat, thin, luminous discharge in the equatorial plane of the terrella. Under ideal conditions, he could produce plane rings sharply intercepting the glass windows. He wrote that if he had been in possession of sufficient quantities of pure radium bromide, he would have coated the equator of the most highly magnetized terrella and observed whether rings of $\alpha$ - and $\beta$-rays would develop in addition to the rings of cathode-rays. This comment reflects the prevailing conception at the time of matter as composed of neutral atoms and the three known types of corpusclar rays. Later, however, Birkeland expressed ideas about interplanetary matter which were much closer to the modern concept of dusty plasmas.

In 1910, during the passing of Halley's comet, Birkeland formulated an explanation on the formation of the comet's tail. He suggested that as the comets approach the Sun, they are charged to a high negative potential by cathode-rays emanating from areas around the sunspots. An anodecathode relationship is set up and a visible discharge takes place in the outstreaming gas from the comet core. Also this theory was tested in the laboratory. It was believed that the comet cores were carbonaceous; and he performed numerous discharge experiments with carbon in different forms over a metallic cathode in the vacuum container. The rapid disintegration and light emission from the carbon confirmed Birkeland's idea that the visible tail is formed by the outstreaming gas "ignited" by a discharge. He also simulated the comet by a very thin, hollow silver needle penetrating into the vacuum chamber from the outside. With the pumps in action, and blowing a weak stream of $\mathrm{CO}_{2}$ through the needle into "space", he managed to set up a discharge between the needle and the anode, the needle acting as a cathode. By carefully adjusting the gas flow and the discharge voltage he could get thin pencils of light shooting out from the "comet".

In the description of his first terrella experiment from 1900 Birkeland mentioned that he in some experiments had seen three luminous rings around the terrella. In addition to the rings in the polar regions he had sometimes been able to observe a third one, that encircled the Earth model almost like the rings of Saturn. Later, during his systematic studies of laboratory aurora, he now and then described this phenomenon, which was rather difficult to produce under his standard experimental conditions. Ten years later he started up with systematic simulations of the Saturnian rings. He had discovered that they were easily formed by changing the polarity of the discharge. In fact, this was the same set-up he used for simulating the zodiacal light, but the discharge parameters were different. In a new 70 liter box he created discharges consisting of three and sometimes as much as five equatorial rings around the terrella. His explanation of these rings was similar to that of the zodiacal light. A constant electric radiation from the planet is accompanied by an ejection of tiny material particles he called electric evaporation, and these particles form the rings. The laboratory analogy to this evaporation is what today is called sputtering. Terrella-experiments simulating zodiacal light and rings of Saturn are shown in Fig. 5

For studies of the sputtering phenomenon Birkeland performed several experiments in an evacuated bell jar placed in a strong magnetic field. He investigated the disintegration of palladium cathodes in a powerful discharge, and the deposition of the palladium on the glass walls. In other words, he demonstrated that material can be thrown off from an active cathode and guided by a magnetic field. Also from a magnetic globe, when acting as a cathode in the vacuum chamber, material was thrown off in the equatorial plane. This he deduced from the blackening of glass sheets located near the terrella. He concluded this study by stating that he believed Saturn throws off tons of matter every day in the plane of the rings, and that the rings are constantly replenished. He also speculated that the moons of the planet could have been formed from such ejected matter. Under the influence of gravitational forces, the dust in Saturn's rings would clump together, forming more moons, and at last the dust rings would disappear. Also the planets in the solar system could have been formed by electrically ejected matter from the Sun.

The experiments simulating the zodiacal light and Saturn's rings guided Birkeland to discoveries that appeared to be of great importance. In the years to follow he developed a great theory on the 


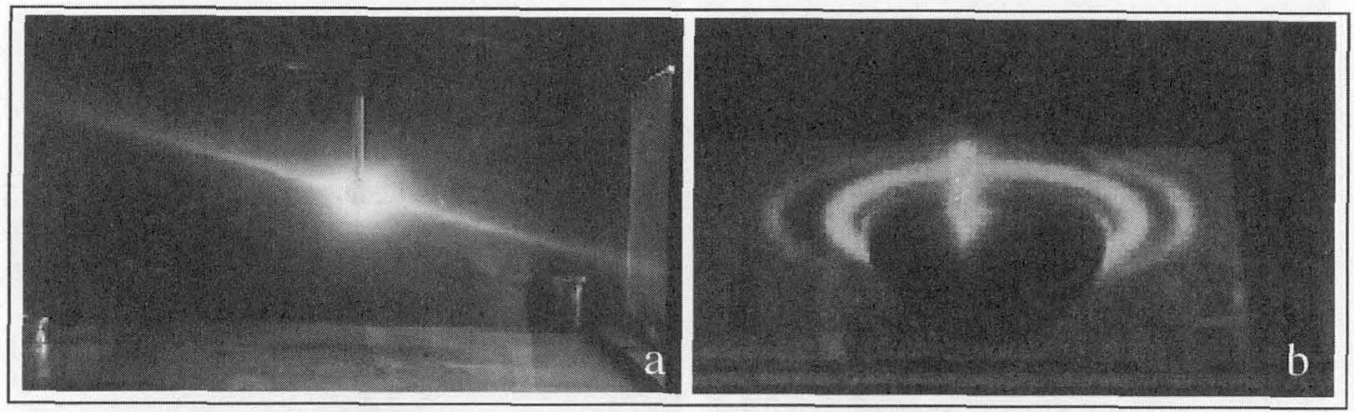

Figure 5: (a) Zodiacal light. In the middle of the picture we have the smallest terrella, $2.5 \mathrm{~cm}$ in diameter, as the Sun. The terrella is covered with a glow, the solar corona, and the zodiacal light is seen end on as a thin disc of light in the equatorial plane of the terrella. (b) Rings of Saturn. This experiment was performed in the third chamber of 320 liter volume and with the $24 \mathrm{~cm}$ terrella. The terrella acted as a cathode and was strongly magnetized.

origin of the solar system [15]. He believed that the sunspots were foot-points of huge disruptive electric discharges from the sun into space, which again were the source of aurora borealis, the zodiacal light and even the planets. During earlier experiments he had seen that disruptive discharges could radiate from points on the cathodic terrella surface. With a low gas pressure, a very high discharge current and with no magnetic field around the terrella, he could create arcs from points on the surface to the anode disc and chamber walls. This was again the same discharge configuration that produced. the zodiacal light and Saturnian rings, but with different parameters.

These point discharges, which were spread all around the surface of the terrella, were interpreted by Birkeland as small sunspot models. He observed that the spots were easier to make when the surface was rough. When introducing magnetic field on the terrella, he observed that the spots were grouped in two zones at a certain northern and southern magnetic latitude. By increasing the field the zones moved closer to the equator of the sphere. At increasing magnetic field the sunspots turned into luminous bands which coalesced at the equator.

After running discharges, he took out the terrella and studied it in a microscope, and observed small craters where the spot discharges had been. This observation supported his hypothesis that mass is thrown out from the Sun during solar flares. Some of this atomic dust, falls back to the surface of the Sun, some disappears into Space, and some will end up orbiting the Sun, and slowly clump together and form planets. He considered the asteroid belt as masses halfway in the process from solar dust to planets.

With an increased gas pressure the pencils of rays were no longer emitted radially from the globe surface, but formed star-like shapes or vortices around the eruptive spots. He considered this phenomenon as being very important, and tried to photograph them. His vacuum chambers, however, did not work to his expectations, and consequently a new 320 liter chamber was built in which he continued his simulations of the sunspots, now using a $24 \mathrm{~cm}$ terrella. It turned out not to be easier to produce sunspots in this chamber in the conventional way, but he could easily produce spot-like discharges by changing the polarity. With the globe as the anode, and the rough and unpolished top and bottom plates of the chamber as the cathode, he could set up "fireworks" of point discharges with the footpoints on the plates.

In one set-up with low pressure, no terrella field, and low discharge current he got phenomena where the entire terrella was covered by the cathode glow. This was described by Birkeland as "a light that resembles the sun's corona". In this 320 liter chamber he performed experiments on the zodiacal light, Saturnian rings, sunspots, the Sun's corona and space propulsion by cathode rays. 


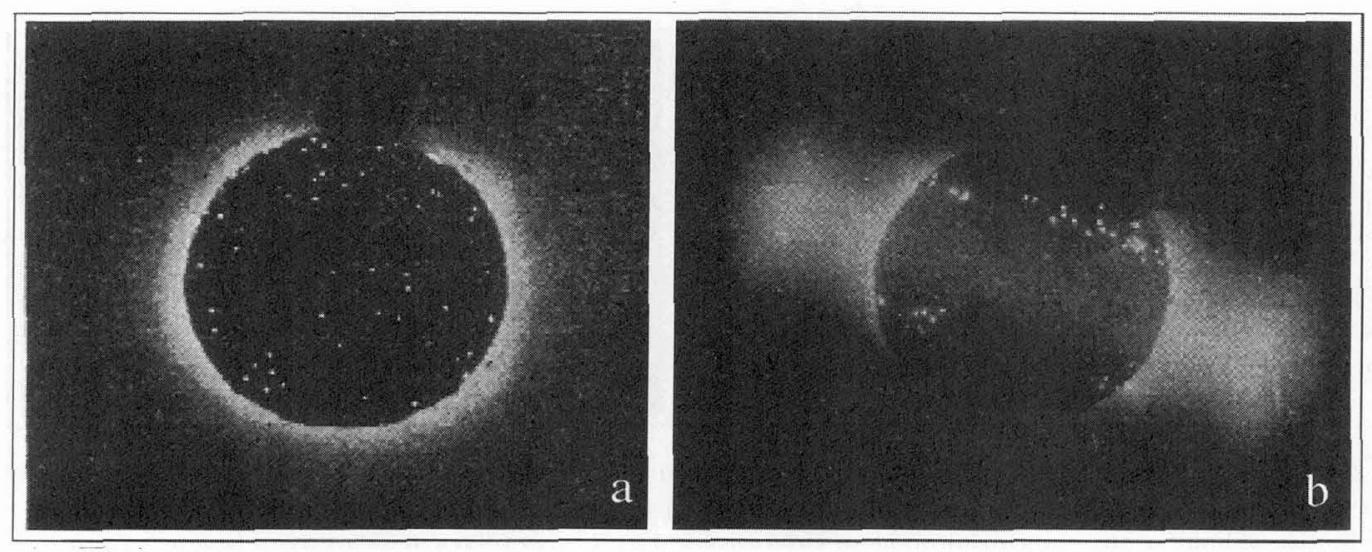

Figure 6: The photos show "sunspots" on one of the smaller terrellas. The spots are hot-spots on a rough cathode surface (the terrella) in a high current discharge. With no magnetic field the spots spread all over the terrella (left), while with a magnetic field present the spots are concentrated in two belts (right).

However, as the experiments became more refined, it turned to be a disadvantage to have the floor and ceiling made from magnetizable steel plates, in particular with big terrellas. Many phenomena were influenced by the magnetism of these plates, and the problem could only be solved by using a different alloy and by further increase in chamber dimension. His next chamber had a volume of 1000 liters, with a $36 \mathrm{~cm}$ terrella. This time floor and ceiling would be made of bronze, and thickness of glass plates for the windows was designed to be $5.0 \mathrm{~cm}$.

Birkeland expressed satisfaction and joy over the simplicity and also the beauty of the experiments in this vacuum chamber. He noted that the experiments became increasingly interesting as the scale was increased. A glance could now be enough to show the occurrence of phenomena that earlier, only with much trouble, could be deduced from a long series of experiments. The one and only auroral simulation in this chamber was described as "remarkably beautiful".

The studies of simulated solar and cosmic phenomena were not performed in the same systematic way as the lab aurora. Data from the experiments became more scarce, and were almost totally absent in his last experiment in the largest chamber. One gets the impresssion that he now considered the displays behind the glass walls and their resemblance to natural phenomena as sufficient confirmation of his theories. He came closer to his starting point from 1896, using the experiments as a generator of ideas, being well aware that he could not simultaneously model all aspects of a cosmic phenomenon in a glass box. His great speculations about the "origin of the worlds" were undoubtedly inspired by the terrella-experiments, but he certainly had no means by which he could simulate the formation of the solar system and the planets in his laboratory.

From the descriptions of his last experiments one gets the impression that he no longer had the patience and self-discipline to perform series of accurate and systematic laboratory work, in spite of the great advances he had accomplished in experimental techniques during the preceding decade. It is not unlikely that this development was related to his change of interest towards more cosmological problems, which were impossible to investigate in detail in the laboratory. It is also possible, however, that it was a reflection of his reduced physical and mental capacity; which was becoming quite apparent around 1913 .

Diagnostics of the terrella-discharges were limited to visual inspection and photography, and is of course due to the fact that more refined diagnostics were non-existent until $\mathrm{I}$. Langmuir developed the electrostatic plasma probe in 1923. It was Langmuir who first coined the word plasma to characterize an ionized gas, and thus pointed out the necessity of a selfonsistent treatment of particles and field and the importance of collective effects. Birkeland was well aware of the shortcomings of particle 


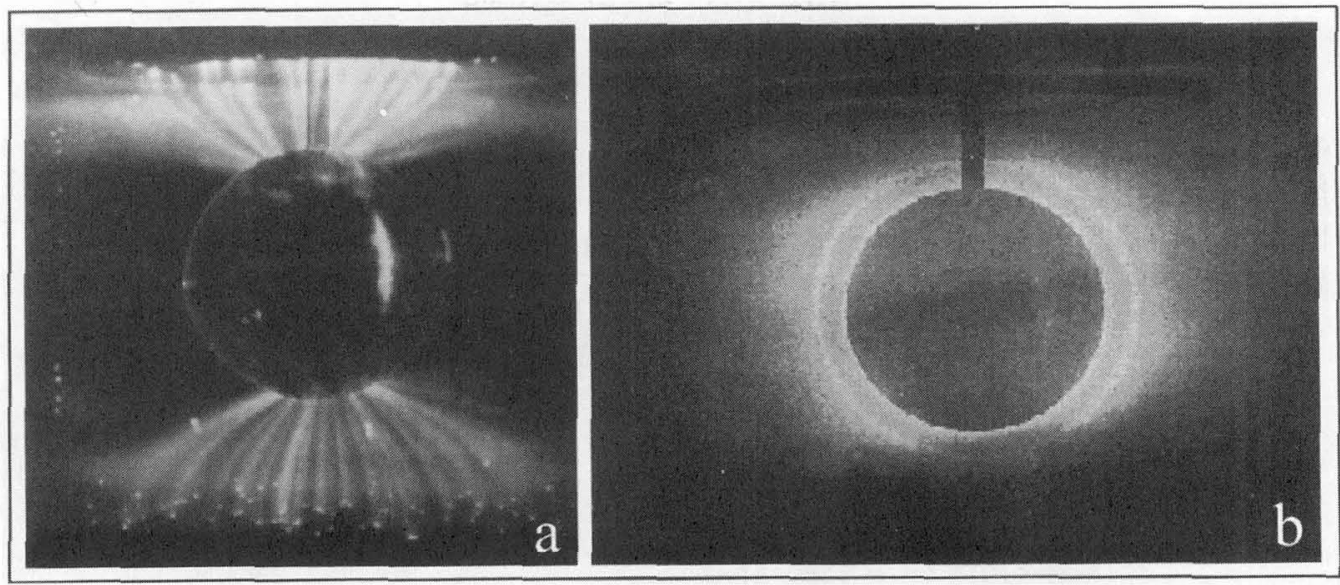

Figure 7: (a) Point discharges done in the 320 liter chamber with the top and bottom surfaces as cathode and the $24 \mathrm{~cm}$ terrella as the anode. (b) Simulation of the Sun's corona performed with the $24 \mathrm{~cm}$ terrella and a very low magnetic field.

tracing in given fields, and in his work on the solar system he struggled with the development of the new concept of a medium consisting of positively and negatively charged particles and dust, governed by electric and magnetic forces. He used a varying terminology for describing the medium filling his discharge chambers and the interplanetary space. Expressions like luminous or rarefied gas, radiant matter, and the fourth state of matter were used at different occasions, where a modern writer would have used the word plasma.

\section{RELATING LABORATORY RESULTS TO GEOPHYSICAL OBSERVATIONS}

On April 5., 1741 O. P. Hiorter in Uppsala discovered that auroral displays seemed to agitate a magnetic needle, and in $1826 \mathrm{H}$. C. Orsted explained this as an electric discharge along the auroral arc. In $1770 \mathrm{~J}$. C. Wilcke noted that auroral rays extend upwards along the magnetic field. Thus, at Birkeland's time geophysicists were well aware of the intimate connection between aurora and geomagnetic field perturbations. In the period 1825-1850 H. Schwabe made systematic sunspot registrations, and in 1844 he discovered the solar sunspot cycle. It was soon realized that the auroral occurence was strongly related to this cycle, and in 1851 E. Sabine showed that the intensity of the geomagnetic disturbances also varied in concert with the sunspot cycle. During the first half of the 19 'th century there was developed a global network of widely spaced magnetometers, which were spread to all the British colonies, and one got methods to separate contributions to the geomagnetic field from currents inside the earth and those arising high in the atmosphere.

After stating his auroral hypothesis Birkeland realized that a closer study of magnetic pertubations would be a key to the understanding of the solar-terrestrial interaction. One problem, however, was that all magnetic observatories were located on lower and middle lattitudes, while the most interesting perturbations were taking place in the polar regions. He organized an expedition to northern Norway in February and March 1897, but this venture was a complete failure, since they were not prepared for the very rough winter conditions in these regions. However, practical experience from this expedition was very useful when he organized the second; and very successful, expedition in 1899-1900. His observations on the two mountain tops, Halddetop and Talviktop during that.winter made it clear that auroral precipitation had to be connected with strong currents in the upper at- 


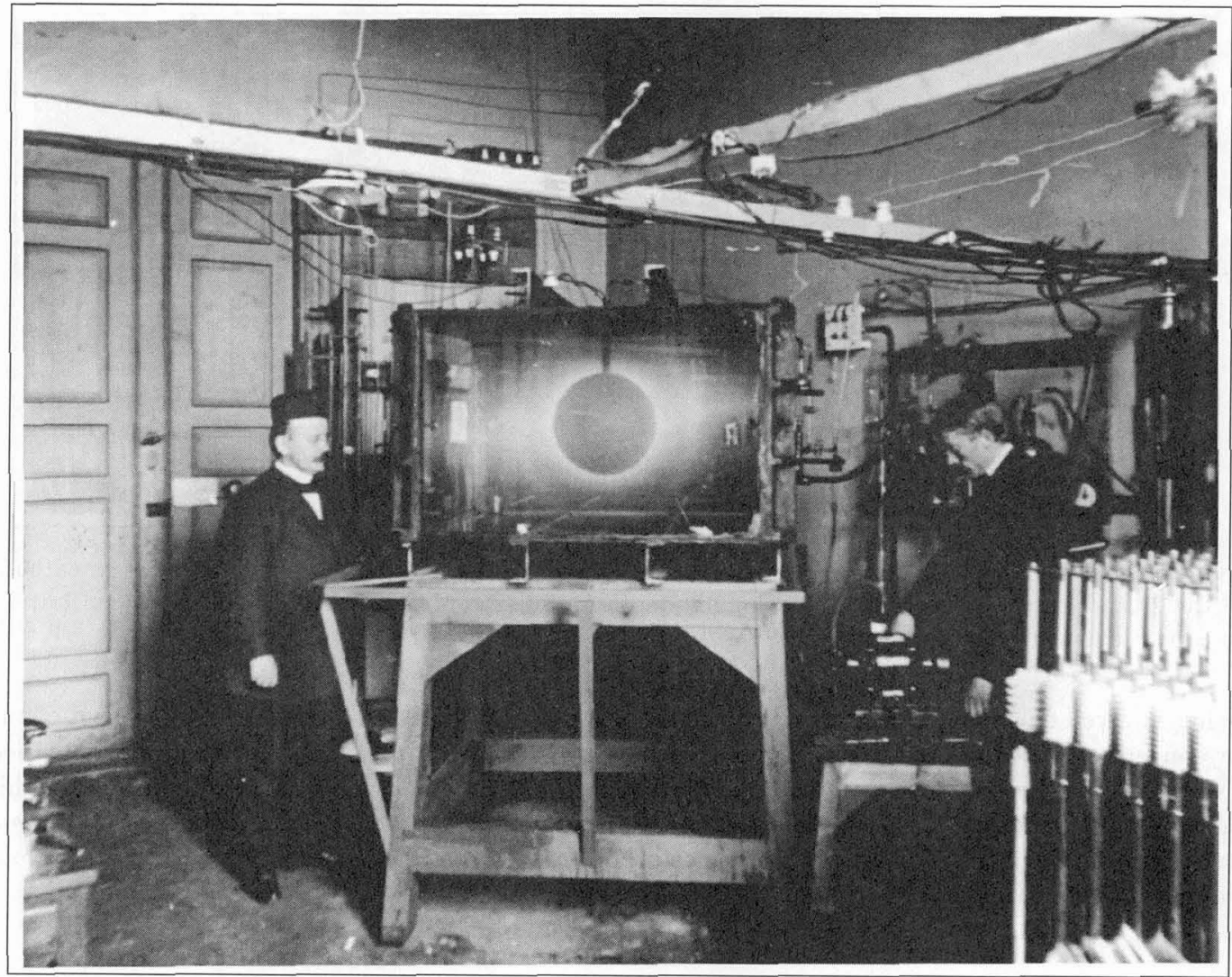

Figure 8: Birkeland and his assistant Olav Devik with the 1000 liter chamber and the $36 \mathrm{~cm}$ terrella (1913). The drawing on the banknote (Fig. 1) was made from this picture.

mosphere, and in his report from the expedition he concludes that the same particles that produce the aurora also produce the electric currents that give rise to the magnetic perturbations. This may seem obvious today, but one should keep in mind that this was only a few years after the discovery of the electron, and it was not generally agreed that all electric currents are carried by subatomic electrically charged particles.

The pattern of magnetic perturbations turned out to be extremely complex, however, and Birkeland felt that further progress required observations of a global network of stations, including the polar region. This was the basis for his third expedition in 1902-1903, where he erected four widely spaced observatories in the Arctic. At these stations he performed magnetic and auroral registrations, measurements of atmospheric electricity and earth currents, and meteorological observations. The registrations from these stations were combined with data he gathered from magnetic observatories around the world, and this made him able to create global maps of magnetic perturbations and current patterns. From meticulous analysis of these current patterns he divided the geomagnetic perturbations into three main categories, the equatorial perturbations, the polar elementary storms, and the cyclo-median storms.

The equatorial perturbations correspond to what now is called geomagnetic storms, and are caused by eastward or westward current perturbations close to the equatorial plane. The existence of such currents can be deduced from Størmer's trajectory calculations, and in modern language they are associated with variations in the westward ring-current caused by energetic particles trapped in 
the Earth's radiation belts.

Birkeland performed terrellarexperiments which demonstrated the existence of the radiation belts. In Fig. 3 we observe a luminous ring, which Birkeland attributed to electrons spiralling eastward near the equatorial plane, constituting a ring current. However, the equatorial perturbations were of two kinds, positive and negative, corresponding to eastward and westward current perturbations respectively, whereas the ring current itself is directed towards the west. In his dicussion of this problem he wrote:

If, on the other hand, we assumed the permanent existence of such a ring, we might imagine the (positive) perturbation to be explained by a diminution in the strength of this current. This explanation is very improbable and unnecessary.

This is what is believed today to be the correct explanation, but Birkeland abandons it. The reason seems to be observations he did with the terrella equipped with a vertical screen. An eastward drift of trapped electrons should give illumination of the west side of the screen. The experiment, however, shows the opposite result, as shown in Fig. 9a. Birkeland could explain this result with a particular class of Størmer-trajectories, but these particles were not trapped, and could not contribute to a. permanently existing ring current. His alternative explanation was very vague, and he admitted that he was far from the final solution. This is an example where the terrella experiments led him astray, and there are certainly many other examples. The important thing, however, is that he pinpointed the problem, leaving the final solution for later investigation.

The polar storms, now called magnetic substorms, represented a more serious challenge, since the magnetic field perturbations seemed very difficult to explain by a horizontal current system alone. After very tedious analysis of a vast amount of data Birkeland concluded that these perturbations were associated with a downward current at one longitude and an uppward current at another longitude, connected by a horizontal current segment through the upper atmosphere at a height of a few hundred kilometers. Current patterns like these could to some extent be supported by Størmer's calculated orbits (Fig. 10a), and he also found support in the terella-experiments in the form of strong luminous bands on a vertical screen along the magnetic field in the late night and early morning sector at high lattitudes as shown in Fig. 9b. These bands were interpreted as due to field aligned currents, which were connected via an east-west current across the night-time sector. But he also discussed mechanisms that were beyond the non-selfconsistent orbit calculations:

In this descent of electric corpuscles, some will occasionally come so near the earth that they will be partially absorbed by its atmosphere, and will then eventually give rise to aurora. If the earth were able to retain an electric charge, we should have approximately horizontal currents, which would be necessary for the production of electrical equilibrium. But secondary electric radiation ought also to begin, and then, as it is still influenced by terrestrial magnetism, give rise to vertical ray-currents. ... Starting from physical considerations, we are thus naturally led to seek to explain the field by a system, which in its average effects, has the character of two vertical currents in opposite directions, connected by a horizontal part.

Thus, it appears that he realized that the auroral particles will ionize the atmosphere, and that horizontal currents may flow across the magnetic field in response to an electric field in this conducting medium. He then assumed that secondary electrons will be accelerated upwards along the magnetic field due to the electric field created by the accumulating space charge from the incoming electrons, and thus closing the electric circuit. This explanation is very close to the modern theories, except for the cause of the incoming flux of particles. According to these theories a potential drop across the earth's magnetotail is induced by the solar wind flow, and this potential difference is projected down onto the ionosphere. During a magnetic substorm, the normal current pattern far out in the magnetosphere is interrupted and short-circuited through the conducting ionosphere, qualitatively 


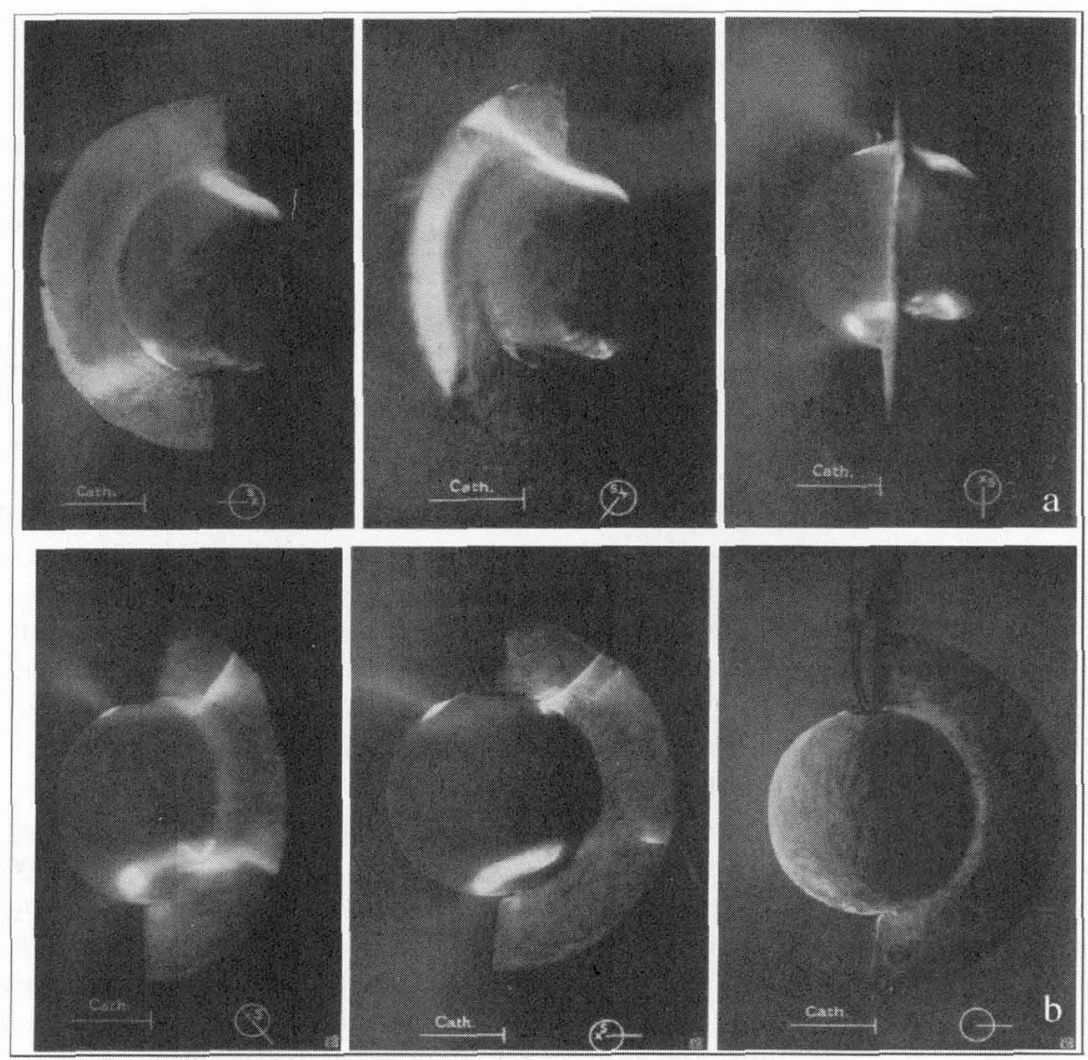

Figure 9: (a) Experiment on ring current effects with vertical screen. Note that the east side of the screen is illuminated, while a current of trapped electrons would illuminate the west side (see dicussion in text). (b) The bright illuminations on the screen along the magnetic field were interpreted as due to field aligned currenta.

in the same way as decribed by Birkeland. This theory has far-reaching consequences, since it underscores that the electric current systems in the Earth's atmosphere are directly coupled to current systems in the interplanetary space. Moreover, the quotation above shows that Birkeland realized that an ionosphere exists, at least in connection with aurora. The ionosphere was discovered by E. V. Appleton in 1925.

In support of this interpretation Birkeland calculated the magnetic field perturbations from various current pattern of this kind, and obtained very convincing agreement with observed patterns. Unfortunately, these results were overlooked by the space physics community for more than half a century, with the result that incorrect theories of ionospheric currents and magnetic storms prevailed until results from satellites confirmed the existence of currents along the magnetic field in 1973 [16]. These currents are now generally called "Birkeland currents".

The cyclo-median storms appear as a large current vortex with the center on relatively low lattitudes. Today they are attributed to high energy photons from solar flares causing currents due to changes in ionospheric conductivity due to increased ionization. Birkeland observed similar current structures with very high energy cathode rays in his terrella-experiments, and Størmer was able to explain these results by calculating the orbits of such particles (Fig. 11).

As for many of the orbit calculations, the energy of the trajectories calculated were very much 


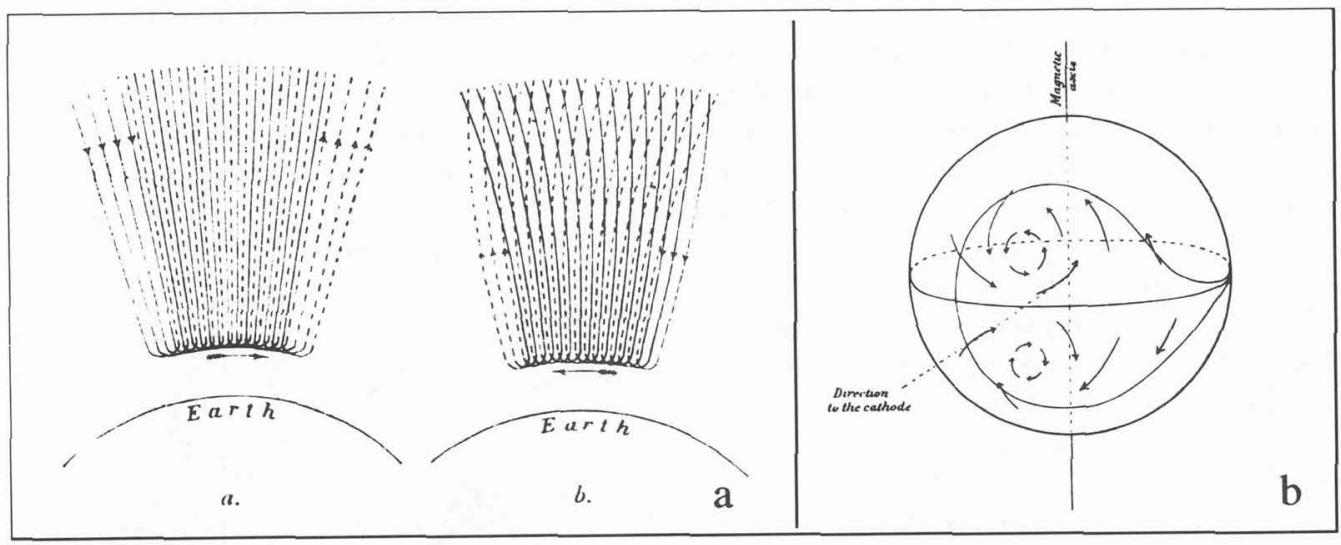

Figure 10: (a) Birkeland's own illustration of the currents during a polar elementary storm. The current pattern yielding the westward horizontal current (left) corresponds to one possible class of Størmer orbits, and the pattern yielding the eastward current (right) to another. In both cases a sheath or curtain of precipitating and returning particles has the net effect of descending currents at one longitude and ascending currents at another, connected by a horizontal current. The wedge shaped pattern agrees with the modern view, but the detailed explanation is different. (b) Birkeland's own illustration of the current pattern associated with cyclo-median storms.

higher than the typical energy for solar wind- and magnetospheric particles (the exception is the radiation belt particles). This means that theories directly based on the orbit calculations have to be modified, and today we know that field and particles will have to be treated selfconsistently. Birkeland was obviously very impressed with Størmer's calculations, but there are also instances where he critisized this approach as being too idealized and ignoring experimental facts. Størmer's theory certainly is more adequate for the terella-experiments than for the solar-terrestrial system, since the early terrella-experiments did not involve a flowing plasma (solar wind).

Geomagnetic observations were not the only registrations made during Birkeland's polar expeditions. Among the many observations done routinely were recordings of auroral forms and occurrence. It was well known at the time that the aurora had a maximum occurrence zone close to $23^{\circ}$ from the magnetic poles, but the exact shape of the auroral oval was not known. The diurnal variation of the

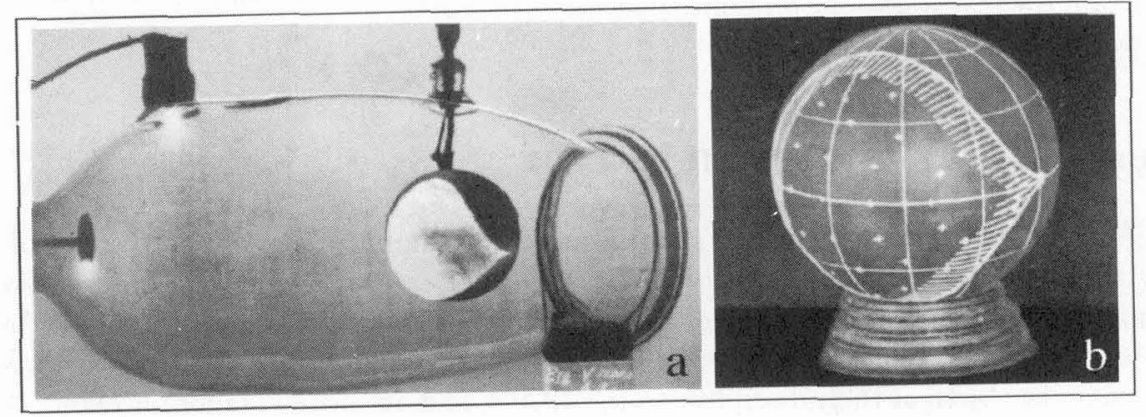

Figure 11: (a) Terrella-experiment showing the region of illumination from high-energy cathode rays. (b) Results of Størmer's calculations for the same case. Compare to Birkeland's drawing in Fig. 10b. 
auroral zone at given location on Earth could be attributed to a deviation of the oval from a circle, but also to the deviation of the magnetic poles from the geographic poles.

In 1907 or 1908 Birkeland performed an elegant experiment to investigate how his artificial aurora behaved when he simulated conditions corresponding to various seasons on the Earth. He made a geometric arrangement where he could position the Earth corresponding to any season and any time of the day (at the magnetic south pole). In this experiment he used the second glass tube of 12 liter volume. It was supported in one end by a hinge which made it possible to incline the tube $23.5^{\circ}$ above and below the horizontal plane. The terrella had a tilted magnetic core and was suspended at the geographical north pole by a universal joint. In this way it always maintained its north-south axis vertical when the tube was inclined. The terrella could be rotated, and since the magnetic axis was different to the geographic axis, he could put the magnetic pole into positions corresponding to different hours of the day and night. The cathode, which represented the Sun, was located in one end of the tube, near the hinge. The terrella was mounted in the other end, near the flat glass plate. With this construction he could simulate variations of the angle between the cathode rays from the Sun and the rotational axis of the Earth by tilting the tube, and thus simulate the seasonal variations. By rotating the terrella around a vertical axis he got the diurnal revolution of the Earth and thus the diurnal movement of the magnetic pole. The arrangement has been reconstructed in Fig. 12.

Fig. 13 shows 8 photos taken at different angles during winter solstice, with the magnetic south pole in the dawn position.

Birkeland considered the spiral shape of the auroral oval as a very significant finding, and made attempts to explain observations of diurnal wandering of auroral arcs from these experiments. These interpretations are mostly obsolete today, but again the investigations pinpointed an

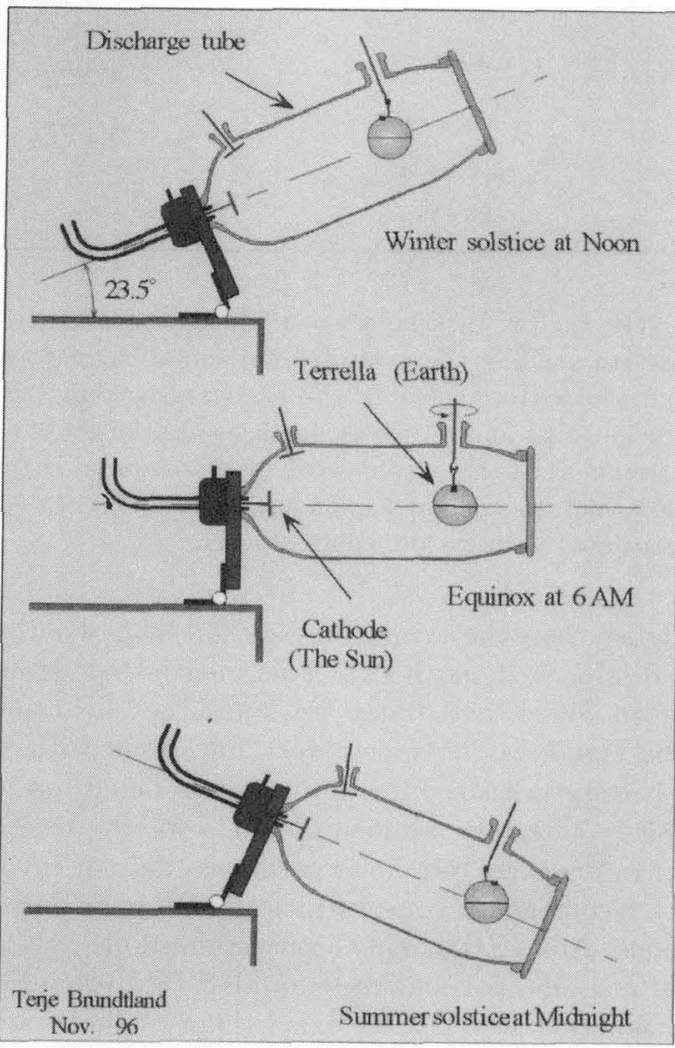

Figure 12: Geometric arrangement for studying seasonal and diurnal variations of the auroral oval. important problem for further study.

\section{THE BIRKELAND - STØRMER LEGACY}

It is an unfortunate fact that Birkeland's work on gas discharges and solar-terrestrial physics was ignored by the plasma- and space-physics communities for more than half a century. After satellite observations began to confirm many of Birkeland's most controversial ideas, the attitude among space physicists changed to one of admiration and almost total acceptance. Plasma physicists, on the other hand, date the birth of their discipline to the 1920's, and are usually ignorant about Birkeland's work. However, the recent Birkeland laudation, based on the realization that many of his ideas have proven to be essentially correct, does not by itself serve the progress of science. In fact, it can be even more important to study the development of incorrect ideas and dead ends, because the right ideas often develop through struggle with competing lines of thought. In one sense, Birkeland's work was 


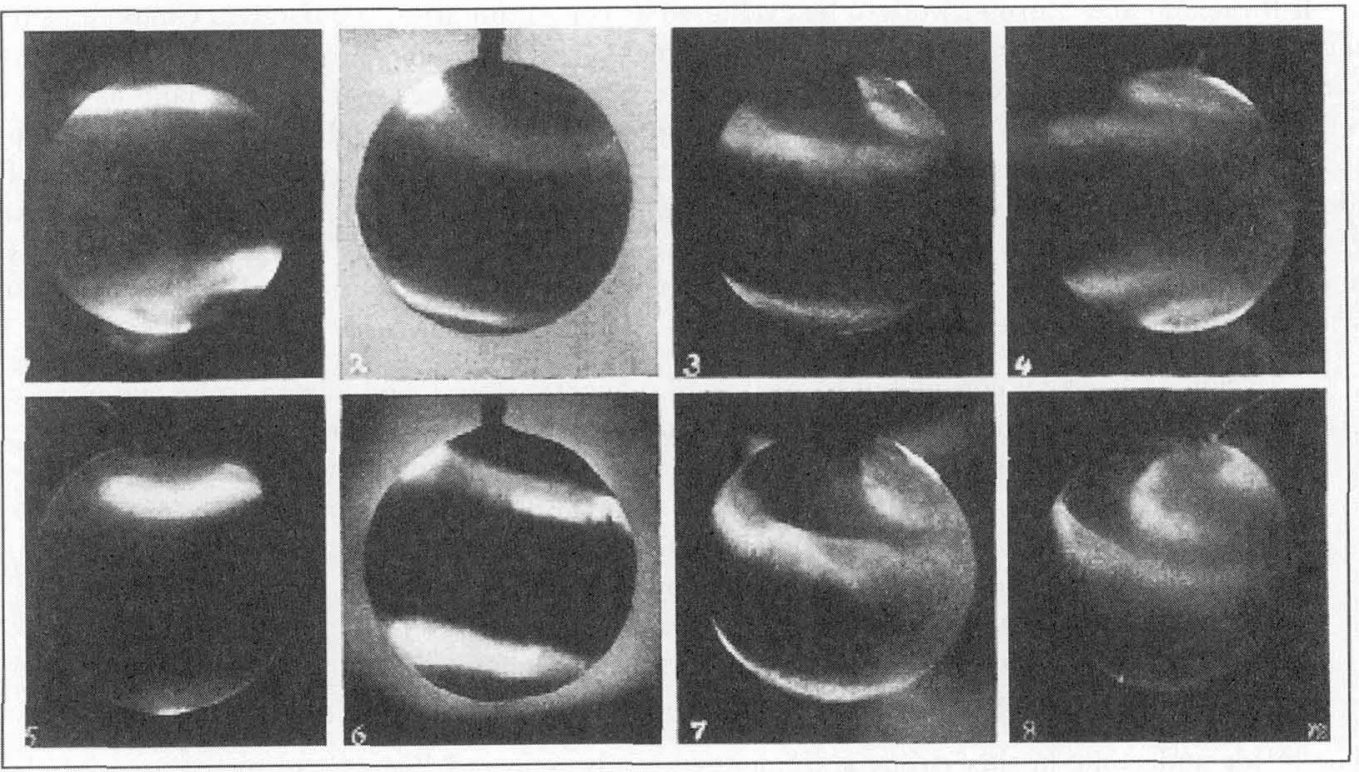

Figure 13: Photos of terrella taken from different camera angles with the tube in the position corresponding to winter solstice and magnetic south pole in the $6 \mathrm{AM}$ position.

doomed to failiure, because it was too far ahead of his time. He wanted to develop a grand theory corresponding to H. Alfvén's Plasma Universe [17], but did not have to his disposal the concepts and theoretical methods of plasma physics. He wanted to investigate and understand in depth discharge phenomena in ionized gases, but did not have the diagnostic tools that were necessary. However, by applying all scientific knowledge and methods available at the time, he was able to formulate comprehensive and consistent theories ready for tests against future advances in physics and technology. The tragedy was, however, that only a handful of scientists accepted the challenge of dealing with the explosive power of Birkeland's theories after his untimely death. One of the few that went against the mainstream was Carl Størmer, another was Hannes Alfvén (1908-1995).

In his opening address to the Birkeland Symposium on Aurora and Magnetic Storms arranged by IAGA in Norway in 1967 Sydney Chapman (1888-1970) had the following comment to the Birkeland - Størmer collaboration [18]:

The apparently unshakable hold, on Birkeland's mind, of his basic but invalid conception of intense electron beams mingled error inextricably with truth in the interpretation of his ideas and experiments on auroras and magnetic storms. As regards to aurora, somewhat the same may be said about Størmer's theoretical work.

Chapman was perhaps the most influential scientist in the field of cosmical geophysics in the period 1920-1960, and was the creator of a mathematically elegant theory for ionospheric current systems and magnetic storms [19]. According to this theory all geomagnetic field perturbations could be explained from a system of currents flowing horizontally in a spherical shell surrounding the Earth, and there was no place for Birkeland's field-aligned currents. Chapman also developed a kinetic theory of ionized gases, found in the last chapter of his famous book with T. G. Cowling [20]. In many respects this theory was obsolete before the first edition was published in 1939 , since it could not describe the collective effects in plasmas which were observed by Langmuir and others [21] a decade earlier. 
If Birkeland and Størmer were to be evaluated as contemporaries to ourselves, Chapman's judgement would certainly be in place. But such judgements create blindness to the weaknesses in our own conceptions, which was exactly what happened to Chapman. By critisizing Birkeland as if he were a contemporary adversary, he missed a golden opportunity to use the old giant's ideas as a stepping stone for further advances. Alfvén did not miss this opportunity, however. Many of Alfvén's basic ideas can be traced back to Birkeland, and this was emphasized by Alfvén himself. In 1987, Alfvén gave the first lecture in a series called "The Kristian Birkeland Lecture" at the University of Oslo, and from the paper based on his oral presentation one clearly observes the strong similarties in their scientific approach. Concerning Chapman's rôle, Alfvén wrote [22]:

Since Chapman considered his theory of magnetic storms and aurora to be one of his most important achievements, he was anxious to suppress any knowledge of Birkeland's theory. Being a respected member of the proud English tradition in science, and attending - if not organizing - all important conferences in this field, it was easy for Chapman to do so. The conferences soon became ritualized. They were opened by Chapman presenting his theory of magnetic storms, followed by long lectures by his close associates who confirmed what he had said. If finally there happened to be some time left for discussion, objections were either not answered or dimissed by a reference to an article by Chapman.

To mention Birkeland was like swearing in the church.

The bitter undertone in this strong statement certainly reflects Alfvén's sentiments associated with his own struggle to achieve recognition for his theories, which usually gained acceptance decades after their publication. But he also attempted to find a rational explanation of this resistance to radical ideas, and attributed this tendency to the increasing specialization of science.

This specialization has also affected the advancement of the ideas of Birkeland and Størmer. Due to the strong influence of the Chapman school, the mathematical achievements of Størmer did not get the attention they deserve. Rather recently, it has been realized that Størmer's problem, the motion of a charged particle in a magnetic dipole-field, is an example of a chaotic Hamiltonian system. Størmer proved that the system has two integrals of motion, and can be reduced to a twodimensional Hamiltonian, which is integrable only for a particular value of the energy integral. In 1970 it was shown that the KAM-theorem applies for small perturbations of this energy, and hence phasespace consists of Cantor-sets of chaotic and regular orbits [23]. This is, in fact, quite apparent just from inspection of the two-dimensional potential corresponding to the reduced Hamiltonian, which consists of three potential "hills" grouped around a saddle point. The problem is structurally similar to the much studied "3-disk problem", where a billiard ball collides with three cylinders placed in the corners of a triangle. One of the most impressive achievements of Størmer and his assistants was their numerical calculations of particle trajectories without electronic computers. More than 18000 working hours were spent on such calculations, and from the drawings and wire-models of these trajectories one gets a clear idea about how sensitive some trajectories are with respect to small changes in the initial conditions. This sensitivity, and its connection to chaos was first discovered in connection with other dynamical systems after it became common to solve such systems on computers. It is interesting to speculate, however, whether chaos-theory would have developed earlier if Størmer's calculations, which probably were the first numerical calculations of chaotic orbits, had been more widely known.

Better known than the intrinsic chaos in unperturbed Størmer orbits is the chaos that may arise from perturbations due to waves or other collective effects. Such effects may be very important for how particles escape from the radiation belts. Recently a very interesting terella-experiment has been set up at Columbia University, where the purpose is to study this radial particle transport in an artificial radiation belt. This experiment is a direct continuation of the work by Birkeland and Størmer, and is highly relevant to the actual geophysical problem [24].

The Columbia University Terrella (CTX) is an example of a class of laboratory experiments where the purpose is to study in detail micro-processes that are assumed to be essential for the 
global dynamics of the solar-terrestrial system. Birkeland's experiments attempted to model the global system itself, but theoretical discussions and a series of terrella-experiments performed at the Royal Institute of Technology in Stockholm in the 50's and 60's have shown that it is impossible to scale all relevant physical parameters down to laboratory dimensions [25]. The scaling problem is being used by many space physicists as an argument for abandoning laboratory experiments a tool in space physics, which claim that large scale numerical simulations are more valuable than experiments. This argument is certainly valid for global laboratory simulations, but it does not hold for the experimental investigation of micro-processes. An example is large three-dimensional MHDsimulation of the magnetospheric cavity, which have proven to be of limited value because ideal MHD is insufficient to describe the global dynamics. MHD breaks down in critical boundary regions like the bow shock and reconnection regions in the magnetopause and the magnetotail. In fact, virtually all the interesting physics that shapes the magnetic topology, energizes auroral particles and so on, occur in such regions. This micro-physics will have to be included in the global models, and this is where laboratory experiment has an important rôle to play.

There is also a widespread reluctance among laboratory physicists against dealing with spacerelated plasma problems. Presumably this is partly due to lack of funding for such type of work, but is probably also due to general ignorance about the wealth of interesting problems space physics can offer the creative laboratory plasma scientist.

A small, but growing, group of scientists from the two communities have sensed this problem, and since 1991 this group has organized four bi-annual workshops entitled "Interrelationship between Plasma Experiments in Laboratory and Space" (IPELS). This workshop, very much in the spirit of Kristian Birkeland, signals a hope for increased awareness of the necessity of an interdisciplinary approach to all sciences that deal with matter in the ionized state.

\section{Acknowledgments}

The authors are grateful to A. Brekke, A. Egeland, H. Pécseli, M. Mauel and B. Bingham for interesting discussions. A special thanks to the staff of the Norwegian Museum of Science and Technology for assistance during the study of old apparatus and written sources.

\section{References}

[1] Birkeland, K., Archives des sciences physiques et naturelles 3ème periode T.33 (1896) 297-309.

[2] Birkeland, K., The Norwegian Aurora Polaris Expedition 1902-1903, Vol. 1, (H. Aschehoug \& co., Christiania 1908 and 1913).

[3] Poincaré, H., C/R. Acad. Sci., Paris, 123 (1896) 930.

[4] Birkeland, K., Archives des sciences physiques et naturelles 4ème periode T.6 (1898) 205-228.

[5] Størmer, C., The Polar Aurora (Clarendon Press, Oxford, 1955).

[6] Egeland, A. and Leer E., IEEE Trans. on Plasma Science Ps-14 (1986)

[7] Egeland, A., "Kristian Birkeland, The Man and the Scientist", Magnetospheric Currents, AGU Geophys. Monograph 28, T. A. Potemra, Ed. (Amer. Geophys. Union, Washington D.C., 1984) pp. 1-16.

[8] Egeland, A., Kristian Birkeland, mennesket og forskeren (Norges Banks Seddeltrykkeri, Oslo, 1994) ISBN 82-7553-017-7 
[9] Röntgen, W. C., "Ueber eine neue Art von Strahlen" (Würtzburger Physik-Med Gesellschaft, Würtzburg, 1895).

[10] Birkeland, K., "De Røntgenske Straaler", (Aftenposten January 22, 1896).

[11] Birkeland, K., Archives des Sciences physiques et naturelles 4ème période T.1 (1896) 497-512.

[12] Thomson, J.J., Phil. Mag. No. CCXIX, October (1897).

[13] Birkeland, K., Expedition Norvegienne 1899-1900 (Videnskabsselskabets Skrifter I. Mat-Nat Klasse 1901. no 1, Christiania, 1901).

[14] Gilbert, W., De Magnete (Dover Publications, Inc., New York, 1958).

[15] Birkeland, K., Archives de sciences physiques er naturelles, 4ème période, T.35 (1913) 529-564.

[16] A McPherron, R. L., Russel C. T. and Aubry M., J. Geophys.Res. 78, (1973) 3131-3149.

[17] Alfvén, H., Physics Today, September (1986), pp. 22, and IEEE Transaction of Plasma Science PS-14 (1986) 629-639.

[18] Chapman, S., "Historical Introduction to Aurora and Magnetic Storms", Proceedings from The Birkeland Symposium on Aurora and Magnetic Storms, Egeland, A. and J. A. Holtet Eds. (Centre Nat. de la Rech. Sci., Paris, 1967).

[19] Chapman, S. and Bartels J., Geomagnetism, vol 1. (Oxford, Clarendon Press, 1962).

[20] Chapman, S. and Cowling T. G., The Mathematical Theory of Nonuniform Gases (Cambridge University Press, London, 1939).

[21] Langmuir, I. Phys. Rev. 33 (1929) 954.

[22] Alfvén, H. and Egeland A., "Auroral Research in Scandinavia", The Kristian Birkeland Lecture 1. (The Norwegian Academy of Science and Letters, 1987).

[23] Braun, M., J. Differential Equations 8 (1970) 294.

[24] Mauel, M., "Laboratory observations of wave induced radial transport within an artificial radiation belt", Topical invited lecture this conference.

[25] Block, L. P., Planet. Space Sci. 15 (1967) 1479-1487. 